\title{
Reconciling Efficiency and Equity: A Global Challenge for Competition Law?* \\ Damien Gerard and Ioannis Lianos (editors)
}

Reviewed by Nuno Castro Marques**

Presented as a tribute to the work and longstanding contribution of Professor Eleanor Fox, the Book, published in April 2019 by Cambridge University Press, gathers the contribution of several well-known authors, all acknowledging the rightness of Eleanor M. Fox's view that "The old gospel of efficiency, not equity, is dead. The two pursuits can move together, in tandem, or apart” (p. 445).

It follows the discussion about the goals of competition policy and embraces directly the question arising from the fact that competition law is multivalued, challenging the Chicago School paradigm - not yet totally refocused by the post-Chicago movement - that efficiency should be the sole concern of competition law and competition enforcers. But it does it through a modern approach, accepting that efficiency is recognisably important and not to be tackled as an "all or nothing" goal, aligning with other recognisable aims instead, in particular equity, and also by presenting that interaction in different markets and sectors, namely in new (and challenging) ones.

Indeed, if there have already been some balancing attempts of the efficiency "paradox" with the control of economic power, protection of economic freedom, consumer protection, among other competition goals and just to quote the most customary, the "mixing" of efficiency and equity is a more rare sight. Indeed, and as already defended by Parret": "Many

\footnotetext{
* DOI: https://doi.org/10.7559/mclawreview.2019.1836.

** Professor at School of Economics and Management of the University of Porto and invited Professor at Porto Faculty of Law, Universidade Católica Portuguesa, 4169 Porto, Portugal.

${ }^{1}$ Laura Parret, L. (2010). "Shouldn't we know what we are protecting? Yes we should! A plea for a solid and comprehensive debate about the objectives of EU Competition Law and Policy", European Competition Journal 6, no. 2: 339-376, 354-355.
} 
authors refer to fairness now as something to move away [...] as fairness is sometimes presented as a thing of the past", but "Fairness has been and still is one of the cornerstones of the [...] competition regime", thus there being no reason for not having its space "in modern competition law, yet it is fairly absent in public rhetoric nowadays".

As it is presented, the Book recognises that "There seems indeed to be significant resistance towards integrating equity and fairness concerns in competition law and conceptualizing this area of law from a social contract perspective", and it "aims precisely to fill this gap" (p. 6). Most probably, it will indeed contribute to bring equity (or fairness) to the core of the competition goals discussion again.

The Book is divided into three parts. Part I ("Framing the Tension between Equity and Efficiency as a Global Challenge for Competition Policy: The Vision of a Pioneer") is clearly dedicated to the tribute due to the coherence and anticipation of the work of Eleanor Fox, with Diane P. Wood ("Eleanor Fox: Insights from an Outsider") recognising that "Not many people thought that Eleanor was wrong [...] but in the end too many people (and I was one, I must admit) thought that the time had not yet come" (p. 26), and Philip Marsden and Spencer Weber Waller ("Citizen Fox and the Vision of Antitrust Cosmopolitanism") recalling that "Much of Professor Fox's early scholarship fought back against the assertion that antitrust was, or should be, solely about consumer welfare as defined as wealth maximization. Her eloquent work on these issues was not opposed to economic analysis, but suspicious of a single strand of neoclassical economics as the master of, rather the servant, of competition policy" (p. 29).

Part II of the Book ("Reconciling Equity and Efficiency: The Challenge of Making Markets Work for People") presents three sections: "Competition for the People"; "Competition against Power"; and "Competition, Inequality and Industrial Policy".

In the "Competition for the People" section, Ioannis Lianos ("The Poverty of Competition Law - The Short Story") rightly defends that competition law "may not reverse the trend towards economic inequality", but it may indeed "fulfil a quite important role in the struggle against economic inequality", and that the "systemic resilience of the social contract may offer a high-end goal that would accommodate both efficiency and fairness concerns" (p. 87). Michal S. Gal ("The Social Contract: Should We Recalibrate Competition Law to Limit Inequality?") reminds that "Competition law, 
like any other form of governmental regulation, is part of the social contract" (p. 88) and "in order for inequality to be reduced, competition law should be one of several tools harnessed for advancing equality and inclusiveness" (p. 108), and Abel Mateus ("Oligarchies, Competition and Development") defends a link between developing countries and weaker markets subject to state-monopolies abuses, questioning "how can such an economy escape from this situation?” (p. 135), although presenting competition law as one of the fundamental tools for that purpose.

In section "Competition against Power", Alan Fels ("The Australian Controversy over Abuse of Market Power Law - A Study in Political Economy") analyses the evolution of the Australian Competition and Consumer Law in the field of abuse of dominance, which is based on the concept of substantial market power, and presents the momentum state of the art deriving from the Competition Policy Review proposal that has produced a draft legislation proposal currently undergoing and that is considered to have been driven by an idea of fairness: "being fair and equitable in that it aims to strike down abuse of market power by business with market power" (p. 219). Ariel Ezrachi and Maurice Stucke ("Antitrust Enforcement and Market Power in the Digital Age - Is Your Digital Assistant Devious?"), after reminding us that "We have paid the price from the efficiency paradox. The wreckage from the economic crisis includes financial institutions deemed too big to fail (or criminally prosecute) and complaints of crony capitalism" (p. 222), analyse through the lens of market power, as competition policy core value, the specific reality of digital markets. And conclude, within a futuristic frame but closer and closer to our daily lives, surrounded with technological devices with the ability to interact with us (simply think about the "ask Siri" or similar), that "Market forces, given the data-driven network effects, have the potential to increase entry barriers, make the strong platforms (and their butlers) even stronger, and weaken many independent personal assistants. [...] The large platforms could extract even more personal data and command even higher rents to allow others to access us. Not only will our pocketbooks be affected. Our political and social discourse could also be manipulated" (p. 240). That conclusion is in some way followed by Josef Drexl ("Economic Efficiency versus Democracy: On the Potential Role of Competition Policy in Regulating Digital Markets in Times of Post-Truth Politics"), whereas he sustains that there may be a case for regulation to protect both freedom of expression and freedom of information on the 
Internet, so as to guarantee that Internet intermediates do not disseminate biased information based on algorithms of their own interest.

Already in section "Competition, Inequality and Industrial Policy", David Lewis ("Competition Policy versus Industrial Policy: Challenging the Mainstream Orthodoxy") makes the apology for equity in the opportunity to participate in the economic activity perspective, and D. Daniel Sokol ("Antitrust, Industrial Policy and Economic Populism") defends that antitrust works better today due to the fact that it has narrower functions. Accepting a broader set of values in antitrust, it should also be considered that democratic accountability may be better performed if some of those broader goals are performed through different instruments other than competition law.

Part III of the Book ("Reconciling Equity and Efficiency: The Challenge of Effective Antitrust Enforcement") is divided into two sections, with section A dedicated to "Designing Effective Enforcement Systems" and section B to "Effective Coordination of Enforcement Systems: A Global Governance Perspective". The first one opens with Albert Allen Foer ("Competition Culture and the Cultural Dimensions of Competition") considering that "Fox has called our attention to context, institutional differences, politics and culture. Culture has probably been the least developed of these concerns" (p. 296), and, when analysing the possibility of a future global antitrust convergence, and accurately pointing that the key factor will be "whether cultural attitudes toward competition and cooperation are relatively weak or relatively strong. Are they malleable enough that universal standards can not only be formally imposed by governments, but also sustained through enforcement over a prolonged period of time? [...] Or [...] will there be a kind of compromise outcome where some areas of antitrust (such as civil anti-cartel enforcement) are susceptible to universal standards while others (such as unilateral conduct by dominant firms) are not?" (p. 301). We are convinced that the latter will be the followed option once competition culture through advocacy gets even more disseminated. William E. Kovacic ("Formula for Success: A Formula One Approach to Understanding Competition Law System Performance") makes an interesting comparison between the competition enforcement system and a Formula One team, stressing that every element is crucial for success: the figure of the team owner is represented by the Political Leadership; the car by the Competition Agency; the driver by the Enforcement Agency Leadership; the team crew by the Administrative and 
Professional Staff of the Agency; the circuit by the Collateral Institutions that also influence the path; and the weather by the Economic, Political, and Social Atmosphere. To be successful - i.e., for an effective enforcement at the right level of competition law -, all of these elements must concur in satisfactory terms. And Edward M. Iacobucci and Michael J. Trebilcock ("Evaluating the Performance of Competition Agencies: The Limits of Assessment Methodologies and Their Policy Implications") add their reflections on the existing methods for evaluating competition agencies' performance. In a different (private) side of enforcement, Daniel A. Crane ("Toward a Realistic Comparative Assessment of Private Antitrust Enforcement") points out the discrepancies between private antitrust as scripted and as practiced and considers that, contrary to the mainstream discourse normally focusing on all positive things surrounding the private enforcement, one should "pay careful attention to the facts on the ground, to learn how antitrust systems really work rather than just theorizing about them". And for a very interesting approach on also a crucial aspect for enforcement - centralised versus decentralised enforcement systems -, Daniel L. Rubinfeld ("Antitrust Enforcement in the U.S. and the EU: A Comparison of the Two Federal Systems") makes a comparison between the US and the EU systems, concluding that due to the subsidiarity principle applicable in the EU and Member States level allocations "as it currently stands the EU antitrust regime offers a clearer delineation of powers and functions than does the US system" (p. 363), although missing several important elements from the former, such as a higher accountability or scrutiny. The absence of part of those elements may be filled by the ECN Plus Project, just as Giorgio Monti ("Galvanising National Competition Authorities in the European Union") states, considering that "ECN can serve as a way of ensuring that NCAs do not take decisions that benefit national champions [... and] This is not very different from 'convergence' discourse we find at the International Competition Network level, but with greater legislative and executive control" (p. 381).

Already in section B of Part III, Dennis Davis analyses the complex questions arising from international cartels and cross-border effects ("Extraterritoriality and the Question of Jurisdiction in Competition Law"), and Petros C. Mavroidis and Damien J. Neven discuss the different international fora where global antitrust policy may be developed, to end up with the profound analysis of Damien Gerard ("International Enforcement Cooperation and the Dynamics of Convergence") of that 
effective international cooperation already existing at EU level through the ECN network, and discussing the limits of the convergence that in his opinion arises when changing the specific framework of the EU context to a multilateral international framework such as in the WTO.

The Book ends with an Afterword of Eleanor M. Fox ("Competition Policy at the Intersection of Equity and Efficiency: The Developed and Developing Worlds"), where Professor Fox sums up her long-lasting thinking: "In the last quarter of the last century in matters of economic law, it was common cause that we could pursue either efficiency or equity but not both [...]. I never believed it" (p. 441). And the evidence is indeed this Book, where several authors, in a coherent set of articles, demonstrate that a post-Chicago competition law paradigm can really be construed based on the balancing of the multiple values defended by competition law, including efficiency and equity/fairness values. 